\title{
IN VITRO SCREENING AND CORRELATION OF ETHANOLIC PEEL EXTRACTS OF PUNICA GRANATUM AND CITRUS SINENSIS WITH RESPECT TO ANTIOXIDANT AND ANTIRADICAL ACTIVITY
}

\author{
AJIT V SONTAKKE, ANUP S HENDRE*, SANGITA R PATIL
}

Department of Biochemistry, Krishna Institute of Medical Sciences, Karad, Maharashtra, India. Email: anupviews@gmail.com Received: 28 March 2020, Revised and Accepted: 20 April 2020

\section{ABSTRACT}

Objective: The objective of this study is to evaluate the effect of the ethanolic peel extracts of Punica granatum and Citrus sinensis on total phenolics, total antioxidants, and radical scavenging activities using different in vitro models.

Methods: Pomegranate and orange fruits at the maturity stage were manually peeled, washed, and air dried before extraction. Dried peels were grinded, weighed, and extracted with $95 \%$ ethanol and were used for in vitro analysis. Different concentrations of extracts for each peel were prepared. Total phenolics content, total antioxidant capacity, and free radical scavenging activities of each peel extract were estimated in the form of Folin-Ciocalteu reagent assay, phosphomolybdenum assay, hydroxyl free radical scavenging assay, and superoxide free radical scavenging assay, respectively.

Results: The ethanolic peel extracts of P. granatum and C. sinensis showed significant increased total phenolic contents and total antioxidant activity. Furthermore, radical scavenging activity (hydroxyl and superoxide) was found to be significant in both ethanolic peel extracts.

Conclusion: It can be concluded from the study that the ethanolic peel extracts of P. granatum and C. sinensis has potential antioxidant and antiradical activity.

Keywords: Citrus sinensis, Hydroxyl radicals, Punica granatum, Superoxide radicals, Total antioxidants, Total phenolics.

(c) 2020 The Authors. Published by Innovare Academic Sciences Pvt Ltd. This is an open access article under the CC BY license (http://creativecommons. org/licenses/by/4. 0/) DOI: http://dx.doi.org/10.22159/ajpcr.2020.v13i7.37668

\section{INTRODUCTION}

Several epidemiological and pharmacological studies evidenced that plants contain biologically active components (e.g., free radical scavengers) that contributes health benefits and protects against degenerative diseases. In fact, oxygen radicals and lipid peroxides have been known for their supposed role in the etiology of many in vivo pathological reactions such as aging and cancer. In this regard, epidemiological studies have shown that consumption of fruits and vegetables is inversely associated with morbidity and mortality of cardio and cerebrovascular diseases and certain types of cancers $[1,2]$.

Many fruits contain different types of antioxidants, such as ascorbic acid, flavonoids, and tannins, which are supposed to play a very important role in the prevention of diseases. In biochemistry and medicine, antioxidants are enzymes or other organic substances, such as Vitamin $\mathrm{E}$ or $\beta$-carotene that are capable of counteracting the damaging effects of oxidation in animal tissues and food. It was stated that besides their endogenous defenses, the consumption of dietary antioxidants, such as phenolic compounds, play a key role in protecting against reactive oxygen species [3].

Plant phytochemicals (e.g., phenolics) have been associated with health benefits as a result of consumption of the higher levels of fruits and vegetables. In industrial practices, synthetic antioxidants have been used as food additives for more than 50 years to prevent peroxidation of fats and oils. Butylated hydroxy toluene, butylated hydroxyl anisole, and tert-butylhydroquinone are effective and common antioxidants preventing oxidation and off flavor development in fats and oils. However, those chemicals are now doubted for their safety and recent literature has expressed safety concerns and health risks associated with their use in food products. Therefore, the attention is now increasingly paid to the development and utilization of more effective, natural, and non-toxic biologically active materials including antioxidants from natural sources such as plants $[4,5]$.

The pomegranate plant (Punica granatum, and Punicaceae family) is a shrub and its fruit is a rich source of bioactive phytochemicals such as tannins and other phenolics. It is a native plant to the Mediterranean region and has been used extensively in folk medicine of some countries in Asia and other parts of the world. Interestingly, it was stated that pomegranate peels have been used since antiquity in the Middle East as colorant for textiles because of their high tannin and phenolic contents [6]. Pomegranate fruit products have been used for centuries since ancient civilizations for medicinal purposes $[7,8]$.

Recently, the interest in the antioxidant properties of phenolic constituents from pomegranate fruits has emerged. Therefore, the purpose of the present study was to evaluate the antioxidant activity of peel extracts using different in vitro methods.

In Asia oranges originated thousands of years ago, in the region from Southern China to Indonesia from which they were spread to the India. It is one of the commercial fruit crops grown in the entire world. 3.23 million tons of citrus fruit was produced in the Egypt which contained 2.14 million tons of the orange in 2008 [9]. Peels are generally wasted while the citrus fruits are mainly used in juice processing industries. Very large amounts of byproduct are formed as wastes during the production of citrus juices [10]. The pollution of environment can also be reduced by this. The oranges peels are rich in nutrients, which can used as drugs or as food supplements too [11].

The antioxidant property present in the plant materials is due to many active photochemical which include the vitamins, flavonoids, terpenoids, carotenoids, coumarins, lignin, saponin, and plant sterols. The Citrus fruits and their juices are an important source of the bioactive 
methanol, the compound is an important to human nutrition which including the antioxidants such as ascorbic acid, phenolic compounds, flavonoids, and pectins. Flavanones, flavones, and flavonols are three types of flavonoids that occur in Citrus fruit [12].

There is lack of information regarding the effects of peel extract on lipid oxidation, antioxidant, and antiradical activity. Therefore, the purpose of the present study was to evaluate the effect of ethanolic peel extracts of $P$ granatum and Citrus sinensis on total phenolics, total antioxidants, and radical scavenging activities using different in vitro models.

\section{METHODS}

All chemicals were of analytical grade, obtained from Loba Chemie, Pvt. Ltd. India.

\section{Plant authentication}

Pomegranate and orange fruits were procured from local market of Karad (Western Maharashtra) India. They were identified and authenticated from the Department of Botany, Yashwantrao Chavan College of Science, Karad. The scientific name, common name, and sources used for the present study are depicted in Table 1.

\section{Preparation of extracts}

Pomegranate and orange fruits at the maturity stage were manually peeled, washed, and air dried before extraction. The dried peels of these fruits were finely powdered using electric mixer grinder, placed in air tight containers and used for further in vitro experiments. Dried powder was weighed and extracted with $95 \%$ ethanol. It was kept in maceration for 15 days at $4^{\circ} \mathrm{C}$ to maximize the extraction. After 15 days, each peel extract was filtered through Whatman filter paper and transferred to a suitable container and kept for analysis.

\section{Antioxidant assay}

Different concentrations of extracts for each peel were prepared. Total phenolics content, total antioxidant capacity, and free radical scavenging activities of each peel extract were estimated in the form of Folin-Ciocalteu reagent (FCR) assay, phosphomolybdenum assay (PMA), hydroxyl free radical scavenging assay, and superoxide free radical scavenging assay, respectively.

\section{FCR assay}

FCR assay was performed by the method of Andressa et al. Ethanolic extract of each peel in different concentrations ranging from $100 \mu \mathrm{l}$ to $500 \mu \mathrm{l}$ was added to each test tube. Distilled water was added to make up volume of $1 \mathrm{ml} .500 \mu \mathrm{l}$ of FCR solution was added to each tube. 500 $\mu \mathrm{l}$ of $100 \mathrm{mg} / \mathrm{ml}$ sodium carbonate was added after $5 \mathrm{~min}$. These tubes were kept at room temperature for $2 \mathrm{~h}$. Gallic acid was used as standard. Absorbance was measured at $765 \mathrm{~nm}$. All assays were conducted in triplicate and mean was calculated [13].

\section{PMA}

Total antioxidant capacity was estimated by PMA by the method of Prieto et al. [14].

\section{Preparation of molybdate reagent solution}

One milliliter each of $0.6 \mathrm{M}$ sulfuric acid, $28 \mathrm{mM}$ sodium phosphate, and $4 \mathrm{mM}$ ammonium molybdate were added in $20 \mathrm{ml}$ of distilled water and volume was made to $50 \mathrm{ml}$ by adding distilled water.

Different concentrations of the ethanolic extracts of peels ranging from $100 \mu \mathrm{l}$ to $500 \mu \mathrm{l}$ were added to each test tube containing $3 \mathrm{ml}$

Table 1: The plants used for the study

\begin{tabular}{llll}
\hline Scientific name & Family & Common name & Part used \\
\hline P. granatum & Punicaceae & Anar & Fruit peel \\
C. sinensis & Rutaceae & Mosambi & Fruit peel \\
\hline P. granatum: Punica & granatum, C. sinensis: Citrus sinensis &
\end{tabular}

of distilled water and $3 \mathrm{ml}$ of molybdate reagent solution. The tubes were kept incubated at $95^{\circ} \mathrm{C}$ for $90 \mathrm{~min}$. After incubation, all tubes were kept at room temperature for $30 \mathrm{~min}$ and the absorbance of the reaction mixture was measured at $695 \mathrm{~nm}$. Mean values from three independent samples were calculated for each extract. Ascorbic acid was used as standard [14].

\section{Hydroxyl radical $\left(\mathrm{OH}^{-}\right)$scavenging activity}

The scavenging ability of peel extract on hydroxyl radicals was determined by the method of Smirnoff and Cumbes [15]

\section{Preparation of Smirnoff reagent}

About $0.041 \mathrm{~g}$ of ferrous sulfate and $0.32 \mathrm{~g}$ of sodium salicylate were mixed in $100 \mathrm{ml}$ distilled water. About $4 \mu \mathrm{l}$ of hydrogen peroxide was added to it, vortexed for uniform mixing and labeled as Smirnoff reagent. Ethanolic extract of each peel in different concentrations ranging from $100 \mu \mathrm{l}$ to $500 \mu \mathrm{l}$ was added to each test tube containing $4 \mathrm{ml}$ of distilled water and $1 \mathrm{ml}$ of Smirnoff reagent. All tubes were incubated at $37^{\circ} \mathrm{C}$ for about $60 \mathrm{~min}$. The absorbance of reaction mixture was read at 562 $\mathrm{nm}$. Ascorbic acid was used as standard. The percentage scavenging ability on hydroxyl radical of each peel extract was calculated using following formula: Scavenged $\mathrm{OH}^{-}(\%)=[(\mathrm{Ac}-\mathrm{Ae}) / \mathrm{Ac} \times 100]$ Where, $\mathrm{Ac}=$ absorbance of control and $\mathrm{Ae}=$ absorbance of extract [15].

\section{Superoxide anion radical scavenging assay}

Superoxide anion radical scavenging activity of each peel extract was determined by Nishikimi et al. [16]. Ethanolic extract of each peel in different concentrations ranging from $100 \mu \mathrm{l}$ to $500 \mu \mathrm{l}$ was added to each test tube containing $3 \mathrm{ml}$ of Tris- $\mathrm{HCl}$ buffer, $0.5 \mathrm{ml}$ of nitroblue tetrazolium (NBT) chloride, $0.5 \mathrm{ml}$ of reduced Nicotinamide Adenine Dinucleotide (NADH) and $0.5 \mathrm{ml}$ of Tris- $\mathrm{HCl}$ buffer. The reaction was started by adding $0.5 \mathrm{ml}$ phenazine methosulfate (PMS) solution to the mixture, incubated at $25^{\circ} \mathrm{C}$ for $5 \mathrm{~min}$ and then the absorbance was measured at $560 \mathrm{~nm}$ against a blank sample. Ascorbic acid used as standard. The percentage inhibition of samples was calculated as

$$
\text { Scavenged superoxide }(\%)=[(\text { Ac-Ae }) / A c \times 100] \text { Where, }
$$

$\mathrm{Ac}=$ absorbance of control and

$$
\mathrm{Ae}=\text { absorbance of extract [16]. }
$$

\section{Statistical analysis}

A total five sets of samples from each variable were analyzed for antioxidant parameters. Each sample was further conducted in triplicate and all values were the mean of three measurements and expressed as mean \pm standard deviation. The results were analyzed using one-way ordinary analysis of variance (Ordinary ANOVA).

\section{RESULTS}

The ethanolic extracts of pomegranate and orange peels were analyzed by ultraviolet-spectrophotometric method for the quantitative determination of antioxidant capacity and radical scavenging activity.

\section{FCR assay}

The total phenolics content assay was performed by FCR assay. It indicated that total phenolics content was directly proportional to concentration of all extracts. However, standard gallic acid showed highest significance $(\mathrm{p}<0.0001)$ for total phenolics content compared to peel extracts of $P$. granatum and $C$. sinensis. The results of total phenolics content of peel extracts of $P$. granatum, $C$. sinensis and standard gallic acid are represented in Table 2 .

Absorbance of all peel extracts reflects directly the total phenolics content. The order of total phenolics content by FCR assay from different extracts was found as follows: Gallic acid $>C$. sinensis $>$ P. granatum.

\section{PMA}

Total antioxidant activity (TAC) was used to measure in PMA and found extremely significant $(\mathrm{p}<0.0001)$ in all extracts as well as ascorbic 
acid. Increase in total antioxidant capacity was directly proportional to concentration of all extracts and ascorbic acid. Further, TAC in standard ascorbic acid was found to be highly significant $(\mathrm{p}<0.0001)$ when compared to P. granatum and $C$. sinensis in all concentrations. The order of TAC measured by PMA was found as follows: Ascorbic acid $>$ C. sinensis $>$ P. granatum. The results of PMA of all variables are represented in Table 3 .

The absorbance of ascorbic acid standard and all the peel extracts reflects directly the reducing power which is nothing but the total antioxidant capacity.

\section{Hydroxyl radical scavenging activity (HRSA)}

It was found extremely significance $(\mathrm{p}<0.0001)$ in all variable extracts with respect to their concentrations. In hydroxyl radical scavenging activity, ascorbic acid showed extremely significance $(p<0.0001)$ compared with $P$. granatum and $C$. sinensis. The results of the hydroxyl radical scavenging activity of all variable extracts are represented in Table 4.

The order of hydroxyl radical scavenging activity (\% inhibition) from different variables was found as follows: Ascorbic acid>C. sinensis $>$ P. granatum.

\section{Superoxide radical scavenging activity (SRSA)}

Although superoxide anion is a weak oxidant, it gives rise to formation of toxic hydroxyl radicals as well as singlet oxygen, both of which involve in the oxidative stress. In the PMS/NADH-NBT system, the superoxide anion derived from dissolved oxygen from PMS/NADH coupling reaction reduces NBT. The decrease in the absorbance indicates the consumption of superoxide anion in the reaction mixture [16].

Extremely significant difference $(\mathrm{p}<0.0001)$ was found among all variables. In SRSA, ascorbic acid revealed extremely significance ( $\mathrm{p}<0.0001$ ) compared to P. granatum and C. sinensis. The results of SRSA of different variable extracts are represented in Table 5.

SRSA (\% inhibition) was found in following order: Ascorbic acid > C. sinensis $>$ P. granatum.

\section{DISCUSSION}

In the past few years, an increased attention has been focused on the industrial wastes, especially those containing residual phenols from the used plant raw material. The previous investigations reported that the phenolic concentration presents in pomegranate peel extract varied from $5 \%$ to $46 \%$ [2,3]. The variability in total phenolics among studies could be partially attributed to differences in solvents used for extracting peels, geographic sources of samples and pomegranate varieties. Polyphenols are one of the most occurring phytochemicals in plants. In addition to their contribution to color and sensory characteristics of fruits, phenolics also play a very important role in providing protection against in vivo and in vitro oxidation.

Table 2: The total phenolics content of peel extracts of P. granatum, $C$. sinensis, and standard gallic acid

\begin{tabular}{|c|c|c|c|c|c|c|c|}
\hline \multirow[t]{2}{*}{ Concentration of extract $(\mu \mathrm{L})$} & \multicolumn{2}{|c|}{ P. granatum } & \multicolumn{2}{|c|}{ C. sinensis } & \multirow{2}{*}{$\begin{array}{l}\text { Gallic Acid } \\
\text { Mean } \pm S D\end{array}$} & \multirow[t]{2}{*}{ F-value } & \multirow[t]{2}{*}{ p-value } \\
\hline & $\mathbf{n}$ & Mean \pm SD & $\mathbf{n}$ & Mean \pm SD & & & \\
\hline 100 & 5 & $0.081 \pm 0.0008$ & 5 & $0.094 \pm 0.0005$ & $0.165 \pm 0.01$ & 5632.7 & $\mathrm{p}<0.0001$ \\
\hline 300 & 5 & $0.115 \pm 0.0015$ & 5 & $0.221 \pm 0.0010$ & $0.438 \pm 0.04$ & 2345.2 & $\mathrm{p}<0.0001$ \\
\hline 400 & 5 & $0.229 \pm 0.0012$ & 5 & $0.332 \pm 0.0007$ & $0.615 \pm 0.03$ & 4023.8 & $\mathrm{p}<0.0001$ \\
\hline 500 & 5 & $0.355 \pm 0.0045$ & 5 & $0.479 \pm 0.0005$ & $0.798 \pm 0.03$ & 8634.5 & $\mathrm{p}<0.0001$ \\
\hline F-value & \multicolumn{2}{|c|}{2854.3} & \multicolumn{2}{|c|}{7639.1} & 121123 & & \\
\hline p-value & \multicolumn{2}{|c|}{$\mathrm{p}<0.0001$} & \multicolumn{2}{|c|}{$\mathrm{p}<0.0001$} & $\mathrm{p}<0.0001$ & & \\
\hline
\end{tabular}

Values were expressed as mean \pm SD. P. granatum: Punica granatum, C. sinensis: Citrus sinensis

Table 3: Total antioxidant capacity of $P$. granatum, $C$. sinensis extracts, and standard ascorbic acid by PMA

\begin{tabular}{|c|c|c|c|c|c|c|c|c|}
\hline \multirow[t]{2}{*}{ Concentration of extract $(\mu \mathrm{L})$} & \multicolumn{2}{|c|}{ P. granatum } & \multicolumn{2}{|c|}{ C. sinensis } & \multicolumn{2}{|c|}{ Ascorbic acid } & \multirow[t]{2}{*}{ F-value } & \multirow[t]{2}{*}{ p-value } \\
\hline & $\mathbf{n}$ & Mean \pm SD & $\mathbf{n}$ & Mean \pm SD & $\mathbf{n}$ & Mean \pm SD & & \\
\hline 100 & 5 & $0.008 \pm 0.0007$ & 5 & $0.042 \pm 0.0007$ & 5 & $0.146 \pm 0.0015$ & 12366 & $\mathrm{p}<0.0001$ \\
\hline 200 & 5 & $0.019 \pm 0.0015$ & 5 & $0.091 \pm 0.0004$ & 5 & $0.336 \pm 0.0012$ & 65423 & $\mathrm{p}<0.0001$ \\
\hline 300 & 5 & $0.072 \pm 0.0005$ & 5 & $0.168 \pm 0.0008$ & 5 & $0.532 \pm 0.0026$ & 72463 & $\mathrm{p}<0.0001$ \\
\hline 400 & 5 & $0.517 \pm 0.0006$ & 5 & $0.680 \pm 0.0011$ & 5 & $0.866 \pm 0.0022$ & 274398 & $\mathrm{p}<0.0001$ \\
\hline 500 & 5 & $0.851 \pm 0.0010$ & 5 & $0.949 \pm 0.0009$ & 5 & $0.984 \pm 0.0007$ & 494032 & $\mathrm{p}<0.0001$ \\
\hline F-value & \multicolumn{2}{|c|}{32142} & \multicolumn{2}{|c|}{45183} & \multicolumn{2}{|c|}{59038} & & \\
\hline p-value & \multicolumn{2}{|c|}{$\mathrm{p}<0.0001$} & \multicolumn{2}{|c|}{$\mathrm{p}<0.0001$} & \multicolumn{2}{|c|}{$\mathrm{p}<0.0001$} & & \\
\hline
\end{tabular}

Values were expressed as mean \pm SD. P. granatum: Punica granatum, C. sinensis: Citrus sinensis, PMA: Phosphomolybdenum assay

Table 4: The hydroxyl radical scavenging activity of all variable extracts ( $\%$ inhibition \pm SD)

\begin{tabular}{|c|c|c|c|c|c|c|c|}
\hline \multirow[t]{2}{*}{ Concentration of extract $(\mu \mathrm{L})$} & \multicolumn{2}{|c|}{ P. granatum } & \multicolumn{2}{|c|}{ C. sinensis } & \multirow{2}{*}{$\begin{array}{l}\text { Ascorbic acid } \\
\text { Mean } \pm \text { SD }\end{array}$} & \multirow[t]{2}{*}{ F-value } & \multirow[t]{2}{*}{ p-value } \\
\hline & $\mathbf{n}$ & Mean \pm SD & $\mathbf{n}$ & Mean \pm SD & & & \\
\hline 100 & 5 & $73.33 \pm 0.027$ & 5 & $74.21 \pm 0.081$ & $79.43 \pm 0.079$ & 10862 & $\mathrm{p}<0.0001$ \\
\hline 200 & 5 & $79.05 \pm 0.063$ & 5 & $76.48 \pm 0.030$ & $81.14 \pm 0.110$ & 28459 & $\mathrm{p}<0.0001$ \\
\hline 300 & 5 & $80.69 \pm 0.122$ & 5 & $82.40 \pm 0.033$ & $84.67 \pm 0.091$ & 21336 & $\mathrm{p}<0.0001$ \\
\hline 400 & 5 & $82.46 \pm 0.167$ & 5 & $84.06 \pm 0.042$ & $86.38 \pm 0.148$ & 19479 & $\mathrm{p}<0.0001$ \\
\hline 500 & 5 & $83.18 \pm 0.206$ & 5 & $85.36 \pm 0.241$ & $88.47 \pm 0.130$ & 6968.2 & $\mathrm{p}<0.0001$ \\
\hline F-value & \multicolumn{2}{|c|}{957.2} & \multicolumn{2}{|c|}{1732.2} & 789.1 & & \\
\hline p-value & \multicolumn{2}{|c|}{$\mathrm{p}<0.0001$} & \multicolumn{2}{|c|}{$\mathrm{p}<0.0001$} & $\mathrm{p}<0.0001$ & & \\
\hline
\end{tabular}

Values were expressed as mean \pm SD. P. granatum: Punica granatum, C. sinensis: Citrus sinensis 
Table 5: The SRSA of P. granatum, C. sinensis peel extracts, and ascorbic acid (\% inhibition \pm SD)

\begin{tabular}{|c|c|c|c|c|c|c|c|}
\hline \multirow[t]{2}{*}{ Concentration of extract $(\mu \mathrm{L})$} & \multicolumn{2}{|c|}{ P. granatum } & \multicolumn{2}{|c|}{ C. sinensis } & \multirow{2}{*}{$\begin{array}{l}\text { Ascorbic Acid } \\
\text { Mean } \pm \text { SD }\end{array}$} & \multirow[t]{2}{*}{ F-value } & \multirow[t]{2}{*}{ p-value } \\
\hline & $\mathbf{n}$ & Mean \pm SD & $\mathbf{N}$ & Mean \pm SD & & & \\
\hline 100 & 5 & $57.19 \pm 0.0148$ & 5 & $71.45 \pm 0.0867$ & $76.69 \pm 0.070$ & 745623 & $\mathrm{p}<0.0001$ \\
\hline 300 & 5 & $65.12 \pm 0.0159$ & 5 & $73.46 \pm 0.0279$ & $78.46 \pm 0.081$ & 792428 & $\mathrm{p}<0.0001$ \\
\hline 400 & 5 & $67.21 \pm 0.0254$ & 5 & $76.48 \pm 0.0537$ & $80.65 \pm 0.125$ & 653119 & $\mathrm{p}<0.0001$ \\
\hline 500 & 5 & $71.60 \pm 0.0952$ & 5 & $79.11 \pm 0.0885$ & $84.90 \pm 0.044$ & 352047 & $\mathrm{p}<0.0001$ \\
\hline F-value & \multicolumn{2}{|c|}{524789} & \multicolumn{2}{|c|}{3954.9} & 956.78 & & \\
\hline $\mathrm{p}$-value & \multicolumn{2}{|c|}{$\mathrm{p}<0.0001$} & \multicolumn{2}{|c|}{$p<0.0001$} & $\mathrm{p}<0.0001$ & & \\
\hline
\end{tabular}

Values were expressed as mean \pm SD. P. granatum: Punica granatum, C. sinensis: Citrus sinensis, SRSA: Superoxide radical scavenging activity

Madrigal-Carballo et al. [7] mentioned that tannins were the major phenolics in pomegranate peels, which were more readily dissolved in $50 \%$ methanol. A mixture of methanol, ethanol, acetone, and water was found to be a better extract of active phenolics from pomegranate peels [2]. The results of our study are in agreement with MadrigalCarballo et al. as we found significant increase in total phenolic contents with increase in the concentration of extracts (Table 2).

Orange peel is one of the important dietary sources of the antioxidant phenolics. The results of present study indicated that the ethanolic extract of orange peel had high amounts of total phenolic contents (Table 2) and this in agreement with Manthey and Grohmann [10].

Plant polyphenolics, a diverse group of phenolic compounds possess an ideal structural chemistry for free radical scavenging activity. Antioxidant properties of polyphenols arise from their high reactivity as hydrogen or electron donors from the ability of polyphenol derived radical to stabilize and delocalize the unpaired electron (chain braking function) and from their potential to chelate metal ions (termination of Fenton reaction) [17].

Parashar et al. investigated the antioxidant and radical scavenging capacity of different extracts of orange peel and they found that the ethanolic extract showed the highest values for total phenolic content, antioxidant activities, and radical scavenging activities [18].

It has been determined that the antioxidant effect of plant products is mainly due to radical scavenging activity of phenolic compounds such as flavonoids, polyphenols, tannins, and phenolic terpenes [19].

The antioxidant properties of flavonoids are due to several different mechanisms, such as scavenging of superoxide, hydroxyl and free radicals, and chelation of metal ions such as iron, copper and inhibition of enzymes responsible for free radical generation [6]

Many researchers have found that in vitro studies on various plants and their parts showed antioxidant properties either by chelating metal ions, chain braking function, scavenging free radicals, or by inhibiting enzymes of free radical generation [20].

In our study, we found significant increased total antioxidant capacity (Table 3), increased hydroxyl radical scavenging activity (Table 4), and increased SRSA (Table 5) which clearly indicated that the observed effects might be due to the presence of phenolic compounds which also indicated strong correlation between total phenolics and TAC found in P. granatum and C. sinensis.

\section{CONCLUSION}

The results from the present study concluded that the ethanolic peel extracts of $P$. granatum and $C$. sinensis have potent antioxidant and antiradical activity and it has also been found that the peels of these fruits possess a greater ability to serve as a source of effective, safer, and better antioxidant and anti-radical agent than synthetic antioxidant. Further research is needed to understand the detailed mechanisms through which these effects are exerted and to study the biological effects of antioxidant rich byproducts of fruits on oxidative stressrelated disorders.

\section{ACKNOWLEDGMENTS}

The authors would like to thank to Krishna Institute of Medical Sciences "Deemed to be University" for providing the facilities to carry out the research.

\section{AUTHORS CONTRIBUTION}

Dr. Anup S. Hendre carried out all the laboratory work. Dr. Sangita R. Patil analyzed the data. Dr. Ajit V. Sontakke wrote the manuscript, compile all the work and finalize the manuscript. All the authors read and approved the final manuscript.

\section{CONFLICTS OF INTEREST}

The authors declare that they have no conflicts of interest in publishing this research article.

\section{AUTHORS FUNDING}

This research received financial assistance from Krishna Institute of Medical Sciences "Deemed to be University" Karad (MS), India. (Letter Number: KIMSDU/DR/215/2016).

\section{REFERENCES}

1. Huang DO, Prior BR. The chemistry behind antioxidant capacity assays. J Agric Food Chem 2005;53:1841-56.

2. Li Y, Guo C, Yang J, Wei J, Xu J, Cheng S. Evaluation of antioxidant properties of pomegranate peel extract in comparison with pomegranate pulp extract. Food Chem 2005;96:254-60.

3. Han J, Weng X, Bi K. Antioxidants from a Chinese medicinal herbLithospermum erythrorhizon. Food Chem 2008;106:2-10.

4. Balasundram N, Sundram K, Samman S. Phenolic compounds in plants and agri-industrial byproducts: Antioxidant activity, occurrence, and potential uses. Food Chem 2006;99:191-203.

5. Reddy M, Gupta S, Jacob M, Khan S, Ferreira D. Antioxidant, antimalarial and antimicrobial activities of tannin-rich fractions, ellagitannins and phenolic acids from Punica granatum L. Planta Med 2007;73:461-7.

6. Moure A, Cruz J, Franco D, Domoanguez J, Sineiro J, Domoanguez H, et al. Natural an-tioxidants from residual sources. Food Chem 2001;72:145-71.

7. Madrigal-Carballo S, Rodriguez G, Krueger C, Dreher M, Reed J. Pomegranate (Punica granatum) supplements: Authenticity, antioxidant and polyphenols composition. J Funct Foods 2009;1:324-9.

8. Murthy KC, Jayaprakasha G, Singh R. Antioxidant activity of pomegranate peel extracts in vivo models. J Agric Food Chem 2002;50:4791-5.

9. Abd El-Aal HA, Halaweish FT. Food preservative activity of phenolic compounds in orange peel extracts (Citrus sinensis L.). Lucrări Stiintifice 2010;53:233-240.

10. Manthey A, Grohmann K. Phenols in citrus peel byproducts: Concentrations of hydroxycinnamates and polymethoxylated flavones in citrus peel molasses. J Agric Food Chem 2001;49:3268-73.

11. Kumar KA, Narayani M, Subanthini A, Jayakumar M. Antimicrobial activity and phytochemical analysis of citrus fruit peels utilization of 
fruit waste. Int J Eng Sci Technol 2011:3:5414-21.

12. Larrauri JA, Ruperez P, Bravo L, Calixto FS. High dietary fibre powders from orange and lime peels: Associated polyphenols and antioxidant capacity. Food Res Intern 1996;29:757-62.

13. Andressa B, Gisely CL, João CP. Application and analysis of the folin ciocalteu method for the determination of the total phenolic content from Limonium brasiliense L. Molecules 2013;18:6852-5.

14. Prieto P, Pineda M, Aguilar M. Spectrophotometric quantitation of antioxidant capacity through the formation of a phosphomolybdenum complex: Specific application to the determination of Vitamin E. Anal Biochem 1999;269:337-41

15. Smirnoff N, Cumbes QJ. Hydroxyl radical scavenging activity of compatible solutes. Phytochemistry 1989;28:1057-60.
16. Nishikimi M, Rao NA, Yagi K. The occurrence of superoxide anion in the reaction of reduced phenazine methosulphate and molecular oxygen. Biochem Biophys Res Commun 1972;46:849-54

17. Hendre AS, Sontakke AV, Phatak RS. Evaluation of in-vitro antidiabetic and antioxidant activity of selected Indian spices. Int J Res Pharm Sci 2018;9:678-85.

18. Parashar S, Sharma H, Garg M. Antimicrobial and antioxidant activities of fruits and vegetable peels: A review. J Pharmacogn Phytochem 2014;3:160-4.

19. Yadav R, Rajviadhya R, Samnani A. Review on antioxidants activity and its evaluation. WJPR 2012;1:41-58

20. Phatak RS, Pratinidhi AK, Hendre AS. Evaluation of antioxidant and free radical scavenging activities of spices mixture extract as additive with reference to synthetic antioxidant. Der Pharm Lett 2015;7:27-34. 